\title{
O DESIGN E O CONCEITO DE ARS MEDIEVAL
}

\author{
Alexandre Schiavoni \\ Universidade Feevale - NH/RS \\ schiavonidesign@yahoo.com.br
}

\begin{abstract}
Resumo: Na Idade Média utilizava-se o conceito de ars para nominar atividades que hoje identificamos como arte, design e arquitetura. As concepções que permeavam o desenvolvimento de projeto e o modo como os medievais apresentavam seus objetos é de difícil compreensão para as modernas categorias de pensamento. Contudo, fazendo-se um breve deslocamento em que se coloca o modus operandi dos designers em contato com a atividade do artifex medieval - aquele que pratica a ars abre-se um rico campo de diálogo. A diversidade e a amplitude das formas de representação e de apresentação dos resultados dos designers modernos - que pensam e manipulam o espaço a partir de recortes, dobras e sobreposições, fornecendo-lhes significados múltiplos - possibilita estabelecer nexos e uma postura compreensiva com o campo da ars medieval. Dito de forma direta, designers estão mais habilitados do que uma série outros profissionais da área de projeto, para compreender a beleza e as peculiaridades de produção da ars medieval não somente porque trabalham explorando o espaço, mas também porque ela está incorporada no processo de estruturação e emergência do campo profissional.
\end{abstract}

Palavras-chave: design, arte medieval, espaço

Abstract: During the Middle Age, the ars concept would nominate the activities that nowadays we identify as art, design and architecture. The conceptions that permeated the project development and how the medievals presented their objects is of difficult comprehension for the modern thinking categories. However, by making a brief displacement of the designers' modus operandi in contact with the medieval artifex - the one that practices the ars - a rich dialogue field opens. The diversity and amplitude regarding manners of results representation and presentation by modern designers - who think and manipulate the space from cuts, folds and overlaps, providing them with multiple significances - enables to establish connections and a comprehensive posture with the medieval ars field. Said in and objective way, designers are more enabled than a serie of other project professionals to comprehend the medieval ars production beauty and peculiarities, not only because they work by exploring the space, but also because the ars is incorporated in the process 
of structuring and emergence of the professional field.

Keywords: design, medieval art, space.

\section{INTRODUÇÃO}

$\mathrm{Na}$ Antiguidade, os gregos utilizavam a expressão téchne para se referir a um modos específico de se fazer ou produzir coisas que na atualidade denominamos de arte, design e arquitetura. Os romanos traduzirão este conceito para o latim utilizando a expressão ars, que possui o mesmo significado da téchne grega e será utilizado até o século XVIII. A noção de ars na Idade Média vai ganhar variados usos significando, em linhas gerais, a arte de bem fazer algo, isto é, o conceito de ars continua com a mesma acepção e atributos da téchne. Desde a ars amandi dos romanos, passando pela ars mechanica dos construtores de catedrais, chegando à ars moriendi dos monges medievais, o saber-fazer vinculado à produção de conhecimento, de estudo, de observação a um conjunto de regras, continua sendo a tônica da concepção. Ainda que na contemporaneidade seja comumente traduzida por arte, não se estava a falar aí sobre a arte no sentido estrito de uma produção plástica e sim de uma prática humana pensada, estudada e conhecida. É o artifex aquele que se dedicará ao exercício da ars. Para o filósofo medieval São Tomás de Aquino, segundo SPEER (2008), a ars é portadora de

(...) uma natureza primariamente técnico-poética, como, por exemplo, o construir e o operar (Summa theologiae I-II, q. 57 a 4 c). Por consequência, cada ars é necessariamente particular; ela relaciona-se sempre a uma finalidade determinada e, portanto, particular, a saber, à finalidade da obra a realizar, e dispõe apenas de meios determinados e limitados [determinata media] para alcançá-la. A ars só experimentará uma apreciação que transcende o seu valor técnico e concreto quando for inscrita em um horizonte muito mais amplo de finalidades humanas. (SPEER, 2008)

Este horizonte a que o autor se refere, no mundo medieval está vinculado à ideia dos mistérios que a natureza apresenta e que cabe ao artifex, se utilizando da ars, revelar. É neste jogo que se estabelecerá o que é belo e que merece ser apreciado. Portanto, não é qualquer produção nem o gesto puro e simples do artifex o que garante a existência de ars naquilo que é apresentado. Há que se estar atento à finalidade, aos meios utilizados e ao seu poder dos seus significados. Em suma, na linguagem dos designers, ao cuidado e atenção no ato projetivo.

\section{ARS MECHANICA E TÉCNICA NO MEDIEVO}

A ideia de ars mechanica, que não era mais do que uma das muitas modalidades que a ars incorporava, a partir da Renascença foi aos poucos assumindo as características daquilo que hoje denominamos técnica (DIAS, $s / d$ ). Este deslocamento se consolida no século XVIII por ocasião da elaboração da Enciclopédia, 
quando Diderot e D’Alembert propuseram-se então a organizar o Dictionaire raisoné des sciences, des arts et des métiers, abarcando todo o conhecimento científico, artístico e técnico a partir do empirismo técnico, pois acreditavam que a única maneira de conhecer seria por sensações no manuseio das coisas; mas, não abandonaram o racionalismo, principalmente quando expresso através das matemáticas. Todos os conceitos derivavam de fatos, mas esses deveriam ser ordenados preferivelmente pela matemática para serem compreendidos (VARGAS, 1996, p. 257).

A matematização do conhecimento sobre a natureza e sobre todas as coisas, que seria levada a efeito pelos enciclopedistas, é uma antiga aspiração do pensamento moderno, remontando a Galileu Galilei e Descartes. O desenvolvimento da reflexão sobre a cinemática e a mecânica iria engendrar, por fim, a ideia de que a natureza e todo o cosmos funcionavam de fato como uma grande máquina regida por uma racionalidade que poderia ser descoberta. O próprio corpo humano passa a ser extensivo dessa noção mecânica. Visto, percebido e estudado como conjunto de engrenagens e sistemas que se relaciona entre si, o corpo é entendido como uma máquina perfeita. A noção de saúde e doença evidentemente compartilha a lógica desta mesma metáfora: saúde, corpo-máquina funcionando dentro da normalidade; doença, máquina enguiçada. Para além do que sugere a metáfora maquínica, há novos conceitos formulados que cumprem com importante papel no plano do pensamento e da produção material a categoria do normal e do patológico (CANGUILHEM, 2002). Não é de surpreender, então, o importante papel que o conceito de ars mechanica vai desempenhar a partir de então.

Como se apontou acima, esse modo de pensar e organizar os saberes era completamente estranho na Idade Média. A novidade e a estranheza não residiam no fato de classificar ou hierarquizar o conhecimento, mas sim no moto que regia este feito. Durante o medievo foram elaborados diversos esquemas classificatórios do conhecimento tendo como referência as Sete Artes Liberais. Nestas organizações por vezes havia um espaço que era ocupado pela ars mechanica que, como regra geral, até o século XII, figurava fora do grupo das ars que se dedicavam à produção de saber. ${ }^{1}$

Havia projetos categorizadores na Idade Média conforme nos relata Meirinhos (2009), contudo, a natureza destas classificações em muito difere da dos enciclopedistas do século XVIII. Não há a crença no poder absoluto da razão e da ciência neste longo arco temporal que vai da Antiguidade ao Medievo. Ainda nesta última Era, o conceito de ciência é herança da scientia aristotélica e é visto como conhecimento demonstrativo, ou seja, "o conhecimento da causa de um objeto e do por que o objeto não ser diferente do que ele é" (COSTA, 2009, p.132).

O conceito de técnica que utilizamos atualmente deriva da ars mechanica medieval incorporada e valorizada no pensamento da Ilustração. Quando, na Era Moderna, a técnica encontrou a ciência viu-se o nascimento daquilo que atualmente é denominado de tecnologia. Responsável por fornecer suporte, status e poder à ciência, a tecnologia é, na contemporaneidade, uma técnica que emprega

\footnotetext{
${ }^{1}$ MEIRINHOS, José. O sistema das ciências num esquema do século XII no manuscrito 17 da Santa Cruz de Coimbra. Revista Medievalista online, ano 5, no 7, dez. 2009, Lisboa: IEM - instituto de Estudos Medievais. Disponível em http://www2.fcsh.unl.pt/iem/medievalista. Acesso em 02/06/2012.
} 
conhecimentos científicos. Corrige o equívoco, demoniza a falha e busca alcançar o grau zero de erro na geração e aplicação do conhecimento. Em outras palavras, afasta e elimina o patológico ao criar a norma. Esta é a utopia da técnica e da tecnologia partilhada pela ciência e pela razão, especialmente por aquela identificada por alguns pensadores como razão-prática ${ }^{2}$. É nesse contexto das divisões e das especializações do conhecimento que tem origem o design.

\subsection{Espacialidade e a ideia de 'apresentação' no medievo}

Retomando o argumento, falou-se que na Antiguidade Clássica se utilizava o conceito de téchne que, posteriormente, será traduzido para o latim por ars. O modo realista como gregos e romanos representavam a natureza ou aquilo que era captado pelo olho, forneceu uma referência forte para a produção da arte na Renascença e esta hegemonia do poder do olhar perdurou por vários séculos. Entre estes dois espaços temporais - Antiguidade e Era Moderna - houve uma época - a Idade Média em que a representação assumiu outros contornos e tomou outra direção. 0 naturalismo-realismo do imaginário (pintura e escultura) greco-latino foi substituído por um imaginário mais esquemático do medievo. Poder-se-ia pensar que isto se deveu a uma carência dos artifex da época medieval, que perdeu ou desaprendeu as técnicas do escorço, da perspectiva, do cuidadoso cinzelamento das pedras. Certamente isto é uma ideia equivocada. A simplicidade das imagens do medievo somente existe porque assim aparecem aos nosso olhos. Na realidade, guardam uma complexidade que, no mais das vezes, nos escapa.

As imagens, no medievo, cumprem com importantíssima função. De um ponto de vista, possível de ser pensado a partir da Renascença, seria crível que os artistas medievais deveriam e poderiam ser mais cuidadosos, e isto significa do ponto de vista da Era Moderna, que no medievo poderiam ser mais realistas- naturalistas com aquilo que representavam ou apresentavam. Na sensibilidade moderna ficou a impressão de que houve uma grande ruptura e um enorme prejuízo técnico no modo como os antigos e medievais representam e apresentam suas imagens tanto no Românico como no Gótico.

$\mathrm{Na}$ realidade, o conceito de representação talvez não seja apropriado ao medievo. Talvez apresentação seja mais pertinente. O fato de, na Idade Média, não ser necessário nem importante assinar a obra, que merecia ser apreciada por si só, talvez reforce a ideia de que a preocupação do 'artista' seja apenas apresentar a obra e não representar algo. Este apresentar possui vínculos profundos com a ideia de mistérios que a obra revela. Isto é mais importante do que a perícia - do modo como se entende atualmente esta noção - com que é executada. As obras possuidoras de ars transmitem mensagens. Estas mensagens tem maior relevância do que a representação naturalista (fig. 1 e 2) por si, ou seja, talvez seja mais eficiente e rápido apreender uma determinada mensagem através de uma imagem esquemática do que através de uma imagem repleta de elementos que devem ser lidos e que, certamente,

\footnotetext{
${ }_{2}^{2}$ Para este tema consulte-se HABERMAS, Jürgen. Teoria de la acción comunicativa I - Racionalidad de La acción y racionalización social. Madri: Taurus, 1987; _. Teoria de la acción comunicativa II - Crítica de la razón funcionalista. Madri: Taurus, 1987.
} 
interferirão na mensagem, tornando-a de leitura mais complexa. Não somente a imagem é complexificada, mas também a mensagem. A Gestalt oferece para os designers uma reflexão sobre isto. Os designers gráficos e, mais especificamente aqueles que trabalham no campo da sinalética, refletem e certamente dominam questões desta natureza. A simplicidade de um ícone o torna tão mais eficaz e passível de ser lido corretamente quanto mais estilizada for a imagem resultante.

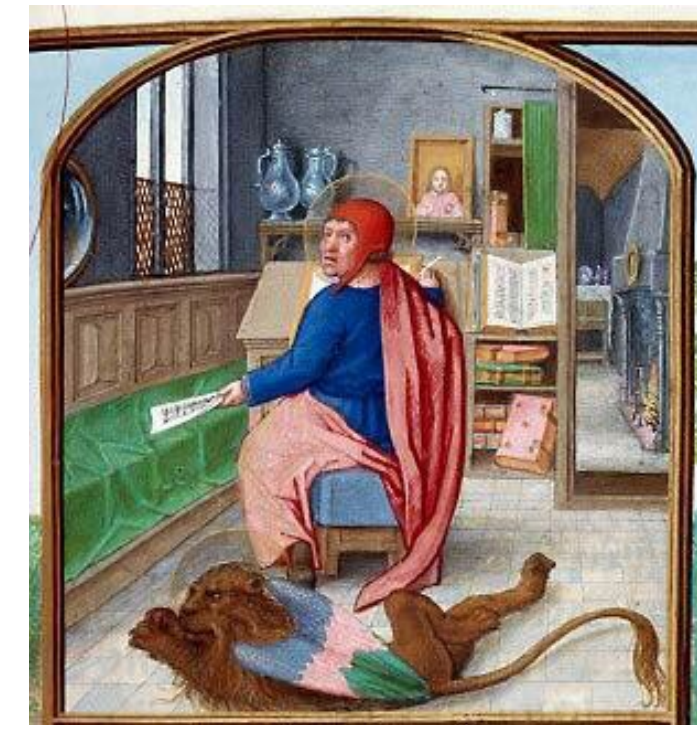

Fig. 1. Saint Marc Heures à l'usage de Rome. Bruges, vers 1510-1525 Rouen, Biblioteca municipal, ms. 3028 (Leber 142), f. 65.

Fonte: Disponível na internet por http em: <http://www.enluminures.culture.fr/documentat i on/enlumine/fr/visites_00.htm> Acesso em 17 mar. 2014

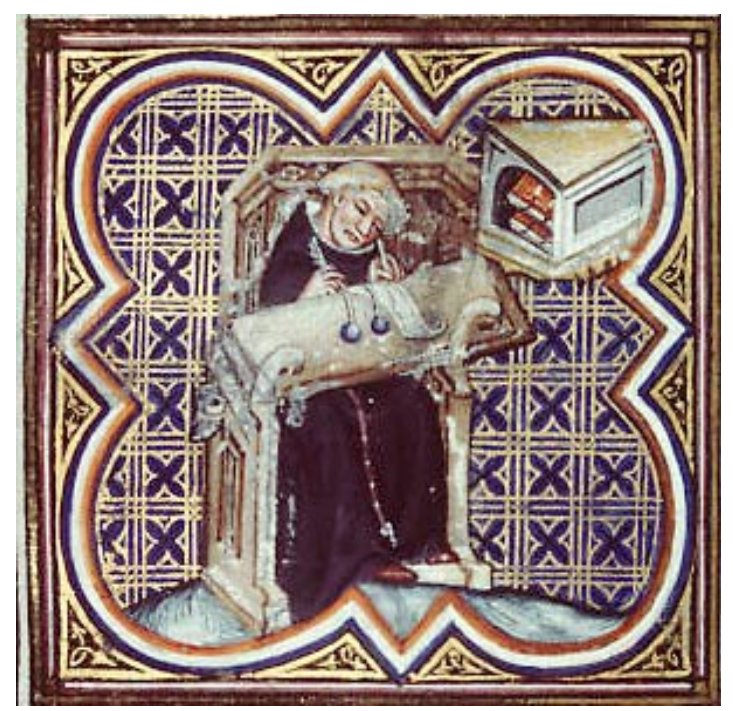

Fig. 2. Posture et outils du scribe (pupitre, rouleau et deux poids pour le maintenir, plume, canif, casier à livre) Gilles de Rome, Le gouvernement des princes, Paris, 1372 Besançon, Bibl. mun., ms. 434, f. 103v.

Fonte: Disponível na internet por http em: <http://www.enluminures.culture.fr/documentation/ enlumine/fr/visites_00.htm> Acesso em 17 mar. 2014

Sem dúvida, este é um dos motivos que acentua a importância das imagens no mundo medieval. Como a mensagem, devido ao seu caráter pedagógico, é o cerne da ação do artifex, é necessário que ela seja lida e entendida rapidamente. É necessário que o leitor se atenha ao que é necessário ser desvendado e não se perca em pormenores que poderiam cumprir com outra função além da decorativa. Não se está afirmando que não havia preocupação com a fruição ou com a beleza - como entendida atualmente - da obra produzida. Afirma-se, sim, que o modo como são produzidas as imagens no medievo, é motivado, é intencional; não é resultado de carências, deficiências ou esquecimento de técnicas. Mas há outros motivos.

\subsection{Contemplação, espaço e perspectiva}

Um dos motes que auxiliam a compreensão da obra contendo ars na Idade Média é o substrato religioso que permeia todas as esferas da vida neste período. As coisas existentes são possuidoras de beleza e feiura, tal qual pensavam os sábios estetas antigos. Contudo, para além do feio e do belo, há mistérios nestas coisas que 
devem ou podem ser revelados. ${ }^{3}$ Grosso modo, tudo o que foi criado, o foi na sua plenitude. No medievo, talvez mais profundo e mais interessante seria não apenas contemplar as belezas e feiuras disponíveis, mas sim entender os seus mistérios. Estabelecer nexos entre as coisas criadas fazendo-as dialogarem entre si. Deus já as criou na sua plenitude e povoou o mundo com elas. Querer apresenta-las tal qual elas são em sua realidade primeira é querer se aproximar de Deus de um modo enviesado e perigoso, talvez querendo imitá-Lo ou se igualar a Ele. ${ }^{4} \mathrm{Em}$ se pensando em termos de representação das coisas criadas e/ou existentes, certamente haverá uma grande tensão entre as noções de mimese - tanto platônica como aristotélica - e o fazer do artifex, porque a representação naturalista-realista, na sua máxima expressão, ao fim e ao cabo, seria um pecado. Neste sentido, o ato de apresentar coloca um número menor de problemas do que aquele que se propõe a duplicar o existente.

O papel da contemplação é importante por isso. Esta postura filosófica do homem medieval é, com toda a certeza, bastante diversa daquela que será assumida na modernidade quando se passa da contemplação para a observação. A postura de observação abre a possibilidade de análise, ou seja, de desmembramento do todo em partes que passam a ser examinadas. É outra operação do olhar: é um olhar persecutório, desconfiado, repleto de dúvida, aquele da dúvida metódica desenvolvida posteriormente por Descartes.

Neste caso, o olho e o olhar são compreendidos como um fim. $\mathrm{O}$ ato retiniano de captação de uma imagem e a representação da mesma de modo coincidente, após a Renascença, é suficiente para chancelar a verdade daquilo que é visto e representado ${ }^{5}$. Há algo confuso nesta concepção. O olhar como produção do pensamento sofre uma derrisão. Desconsidera-se o fato de que o final do processo se dá, em qualquer caso, no plano do pensamento e não no ato de captura de uma imagem. Assim, examinando algumas imagens medievais ou mesmo de outras culturas que utilizam outro modo de construir perspectivamente o espaço, tem-se a impressão de que as coisas estão fora do lugar, que estão erradas, ou que são impossíveis. Em realidade, o fato de se abordar determinada cena real de um ponto de vista ou de vários ao mesmo tempo, não altera para aquele que conhece os códigos daquela cultura, o significado do que está sendo indicado na imagem ${ }^{6}$.

Outro motivo para fugir do realismo-naturalismo da representação: a concepção de espaço do medievo difere em muito da nossa, na contemporaneidade. Segundo argumenta WERTHEIM (2001) na visão medieval do universo, havia claramente um espaço para a alma, assim como para os astros e estrelas (o céu

\footnotetext{
${ }^{3}$ ECO, Umberto (org.). História da Beleza. Rio de Janeiro: Record, 2010, cap. IV e V, pp. 99-153

${ }^{4}$ SPEER, Andreas. Tomás de Aquino e a questão de uma possível estética medieval. Viso · Cadernos de estética aplicada - Revista eletrônica de estética, № 4, jan-jun/2008. Disponível em http://www.revistaviso.com.br (acesso em 12 fevereiro 2014).

${ }^{5}$ WERTHEIM, Margaret. Uma história do espaço: de Dante à internet. Rio de Janeiro: Jorge Zahar, 2001, p. 82

${ }^{6}$ Segundo Debray: “ Os egípcios utilizavam a perspectiva horizontal, os hindus a perspectiva irradiante, os chineses e os japoneses a perspectiva a voo de pássaro, os próprios bizantinos a perspectiva invertida". DEBRAY, Régis. Vida e Morte da Imagem: Uma história do olhar no Ocidente. Petrópolis: Vozes, 1994, p. 230
} 
celeste). Predominava uma ideia dualista do problema, ou seja, há a possibilidade de se pensar a existência de elementos da matéria (corpo) e do intangível (alma) convivendo harmonicamente e ao mesmo tempo. O geocentrismo informava que a terra era o centro do universo, definindo nas esferas celestes os limites de cada ente participante daquele universo. Nessa ordem metafísica, a humanidade ocupava o centro do universo que é pensado, então, como finito.

Fora da esfera mais externa estava o "Céu Empíreo de Deus" que, metaforicamente, estava além dos limites do universo: além do tempo e do espaço. Sendo finito, havia nesse "Céu Empíreo de Deus" espaço de sobra para as almas que para lá fossem. Havia, portanto, uma saída teológica para o lugar destinado às almas, que não era um mundo material, mas era, para as pessoas do medievo, real. Essa teoria sobreviveu até que os astrônomos ousaram desafiar a extensão do universo, colocando-o como infinito, e dessa maneira, sem qualquer espaço livre que pudesse ser ocupado pelas almas.

É neste momento que se vê o início do desenvolvimento da teoria mecanicista, que entendia o universo como um intrincado aparato mecânico com regras próprias de movimento e ocupação do espaço. Este mecanicismo, que teve em René Descartes seu maior expoente, redefiniu essa "nova ciência" agora fortemente apoiada na ideia de separação entre a matéria e o pensamento (res extensa $\mathrm{X}$ res cogitans), onde a máxima "Penso, logo sou" "fundava a realidade não no mundo físico, mas no fenômeno imaterial do pensamento." (WERTHEIM, 2001, 26).

Muito distante do dualismo espacial da idade média, no mecanicismo o universo era agora sugerido como infinito. Com a revolução científica e seu espaço agora infinito, não sobrara espaço "separado" passível de suportar armazenamentos de almas ou psiques. Passamos a ter então uma imagem do mundo monista, e não mais dualista. Nessa visão monista, é admitida apenas a realidade física. Assim, afirma Wertheim:

A velha imagem do mundo, com suas almas diligentes e seu espaço celeste, deu lugar a um universo mecânico em que a Terra se tornou um bloco de rocha a girar num vazio euclideano. Além disso, enquanto os medievais viam os homens como seres ao mesmo tempo físicos e espirituais - amálgamas de corpo e espírito -, os novos mecanicistas nos viam num sentido puramente físico. Assim, a visão monística do espaço foi transformada numa visão monística do Homem. (Wertheim, 2001,27)

Esta ideia monista desenvolvida pela nova ciência que atinge o espaço cósmico e o próprio corpo humano (fig. 3 e 4) se estenderá a todas as esferas do pensamento e das práticas cotidianas no Ocidente, alcançando desde uma dimensão política na ideia de formação do Estado Moderno, passando pelo absolutismo das monarquias europeias e se plasmando no modo como se desenvolveu o próprio mercantilismo. 


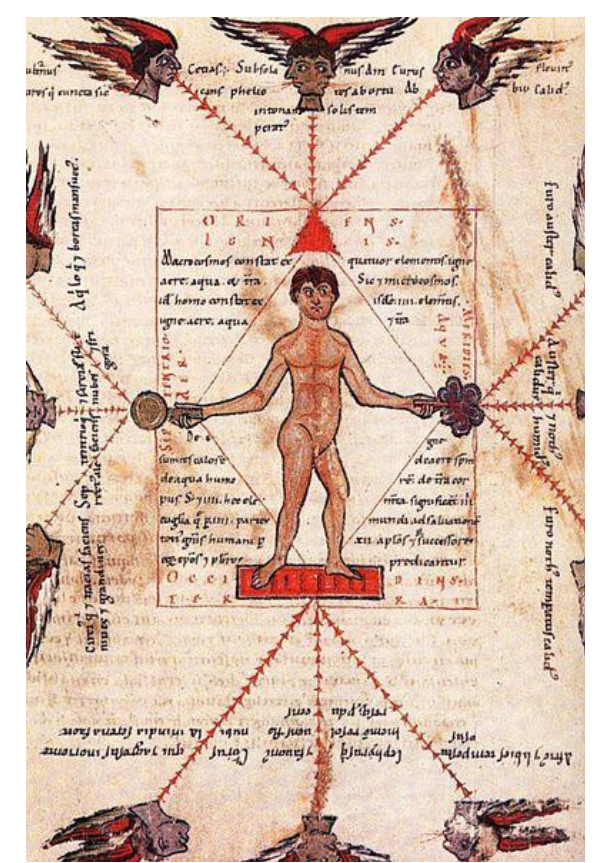

Fig. 3 Representação do Homo Quadratus. Ventos, elementos, temperamentos.

Manuscrito Astronômico da Baviera, século XII. Fonte: ECO, Humberto. História da beleza. Rio de Janeiro: Record, 2010, p. 76.

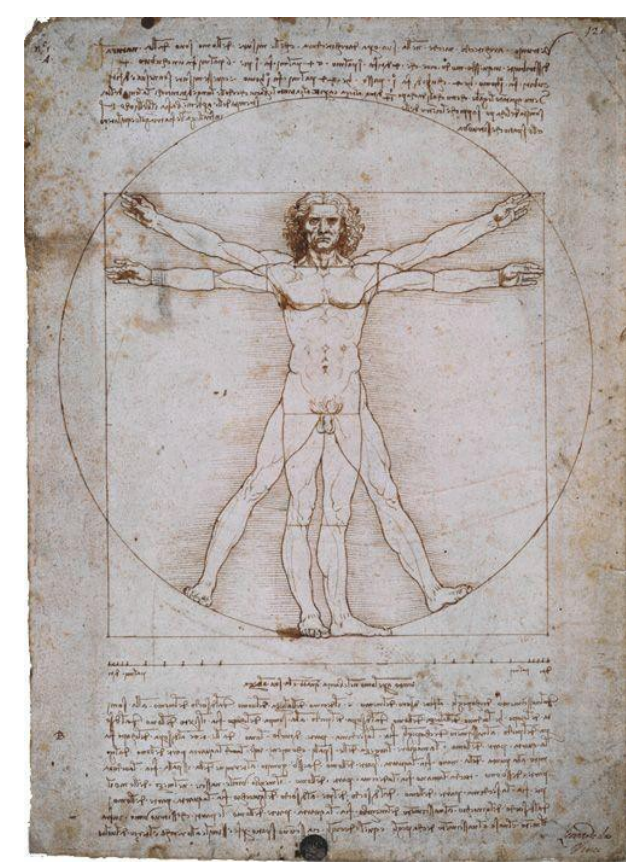

Fig. 40 Homem Vitruviano. Leonardo da Vinci. C. 1490

Fonte: Disponível na internet por http em: <http://www.universalleonardo.org/worklarge. php?

id=448\&image $=0$ \&trail=0\&trail Count $=$ \&name $=>$

A perspectiva linear desenvolvida a partir da Renascença, é outro elemento que marca e materializa esta transformação no modo de pensar e conceber o espaço do medievo à Era Moderna. O materialismo e a matematização do conhecimento, associados à necessidade do desenvolvimento de desenho técnico e científico, cria outros modos de representação pictórica. Na busca pela exatidão e pelo 'grau-zero' de erro, a teoria da perspectiva é, então, a partir do século XVII, deixada pelos artistas como fonte de estudo e passa a ser elaborada por geômetras. Estes vão produzir novos conceitos, fundando a geometria projetiva e descritiva. Para a geometria descritiva a perspectiva é definida como ciência que ensina a representar os objetos tridimensionais sobre uma superfície bidimensional, de tal modo que a imagem representada em perspectiva e aquela dada pela visão, coincidam. Certamente que esta concepção de espaço está muito distante daquela medieval.

\subsection{O nascimento do Design e a noção de ars medieval}

Desde seu nascimento, o design traz consigo a marca da inconformidade, da crítica e da atenção ao tempo presente. Já é bem sabido que os historiadores localizaram seu registro de nascimento no contexto da revolução industrial (HESKETT, 1998; CARDOSO, 2008; MORAES, 1999). Desse modo, é um saber que nasce no campo da modernidade e por isso contém todas as problemáticas que ela trouxe consigo. Emerge o design moderno como uma crítica ao fazer das máquinas, ao produto em série, percebido como de mau gosto e desumanizado. Alargando um pouco mais o campo de visão, a crítica vai além: não somente o produto, mas também o produtor sofre dos mesmos efeitos desumanizadores do contexto industrial. No século XIX, 
William Morris, John Ruskin, os pré-rafaelitas e a Escola de Artes e Ofícios apontavam nesta direção e denunciavam o equívoco do exílio imposto ao "belo" pela produção racionalizada. O resgate da estética na produção da cultura material se dá, na proposta desses autores, pela reintrodução do artesanato no fazer do designer. O fazer artesanal será o responsável pelo ingresso clandestino da arte na elaboração dos objetos de uso. Abre-se novamente aí, a discussão sobre as relações entre arte e artesanato.

O gesto introdutor do valor estético, ainda que remetendo ao artesanato, aliado às transformações tecnológicas ocorridas naquele tempo é, por assim dizer, uma tática de guerra desses primeiros designers. Camuflado pelo discurso do retorno ao artesanato, não estão os designers do século XIX propondo reacionariamente uma volta ao passado? Talvez este aspecto não fique suficientemente claro em textos clássicos da história do design, que insistem em sublinhar este tipo de crítica aos proto-designers modernos como Ruskin e Morris e à Escola de Artes e Ofícios. Primeiro porque, justamente, estes precursores do design moderno se opõem vigorosamente aos estilos historicistas; depois, porque ao se referirem ao artesanato, não o concebem apenas como técnica construtiva, tal qual é concebido na modernidade.

O historicismo, que vigorou no século XIX se caracterizou justamente por um retorno acrítico ao passado. O revivalismo do neogótico, do neobarroco, do neorrococó e todos os ecletismos, com seus excessos ornamentais no desenvolvimento de produtos, deixam em evidência a falta de uma linguagem apropriada à Era da Industrialização (CARDOSO, 2008). O historicismo ou o ecletismo do século XIX são, por assim dizer, um hiato, uma perplexa pausa no campo da cultura material que se sente atrapalhada, ou até mesmo ultrapassada, pelas transformações ocorridas no mundo da técnica e da tecnologia. É, de certa maneira, este o diagnóstico que fazem os precursores do design: não há um estilo ou mesmo uma forma de produção adequada aos novos tempos. A resposta mais acabada a este questionamento é dada pelo movimento de Artes e Ofícios. Em alguma medida ele preconiza a retomada da experiência do artesanato medieval.

Ao se reportar ao artesanato medieval, buscam lá o antigo significado de ars, não o da ars mechanica, que foi traduzida por técnica, mas o conceito geral de ars, entendido como projeto desenvolvido por diferentes saberes que dialogam entre si. Poder-se-ia ir além, sem o risco de forçar o argumento ou os limites do razoável: a referência à ars medieval, lida stricto sensu pelos "pais fundadores" do design como artesanato, aponta para a necessidade da construção de um campo de saberes; um campo interdisciplinar, tal como ocorria na Idade Média.

Sabe-se que a construção de uma catedral e de todos os seus equipamentos não era obra exclusiva de um arquiteto ou de um engenheiro. Nela estavam conjugados os esforços de escultores, pintores, construtores, pedreiros, marceneiros, vitralistas, ferreiros etc. A catedral medieval é resultado de um projeto coletivo para onde convergiam variados saberes, não sendo possível, também por isso, a assinatura da obra. Não seria digno e nem ético, somente o "arquiteto" (e é sempre bom lembrar que a categoria arquiteto não existia na Era Medieval) ou qualquer outro profissional 
se apropriar da autoria da obra. Os mestres da forma e dos materiais que organizavam o projeto eram todos possuidores de excelência naquilo que faziam, eram mestres da ars. Não somente dominavam as técnicas de fazeres próximos ao seu, mas também as tecnologias disponíveis a serem aplicadas no projeto. Evidentemente, eram também mestres do diálogo, haja vista a necessidade do trabalho "interdisciplinar". Era a essas noções que se reportavam os precursores do design quando reivindicavam o retorno ao artesanato medieval.

Seria incoerente e contraditório que após tantas críticas ao revivalismo, o movimento de Artes e Ofícios propusesse um simples retorno ao passado. Observando a produção material do movimento percebe-se o quanto ela está longe de ser uma cópia do modelo medieval, mas, também, o quanto a experiência do medievo lhe foi importante no sentido de acertar o passo com as necessidades impostas pela industrialização. Emerge aí a ideia do projeto como caminho possível para a construção dos objetos numa cultura industrializada.

Outro dado importante para que se questione a ideia de reacionarismo desses primeiros designers, é que, além de propor uma retomada do conceito de ars, eles apontam para os limites da técnica e da tecnologia denunciando seu primado racionalista limitante, corroborando a tese de que estão atentos ao tempo presente. $\mathrm{A}$ técnica e a tecnologia, com sua obsessão pelo acerto, pela exatidão, excluíram do saber, a arte e, junto com ela, boa parte do pensamento. São esses atentos designers que, observando a separação, resgatam lá do mundo antigo, as possibilidades de releitura de conceitos e práticas outrora compartilhadas que foram fragmentadas. No mundo moderno, arte, artesanato, engenharia, arquitetura e aquilo que hoje entendemos por design, foram separadas como campos distintos. $O$ fato é que esta separação não é nova e nem tampouco iniciou no contexto do século XIX. O status de arte maior adquirida pelas artes plásticas em relação à produção artesanal, data da época da Renascença. Ao longo do tempo essa divisão assumiria uma configuração que identifica campos de atuação distintos que foram denominados de belas-artes e artes aplicadas (DONDIS, 1997, p. 7-12).

Esquadrinhamento, enquadramento, separação, delimitação e fixação de campo, construção e sujeição de identidades, fazem parte da lógica operativa das tecnologias de controle e poder. ${ }^{7}$ No nascimento do design, no século XIX, o sistema das divisões estava em pleno funcionamento. Arte, arquitetura, ciência, técnica e tecnologia são separadas na modernidade como saberes distintos e independentes. Arte, ciência e filosofia, a partir da Era Moderna, ocupam lugares distintos no espaço da produção de saberes. As divisões são realizadas não apenas no espaço de fora, nos grandes conjuntos ou fontes produtoras de saber, mas também internamente, dentro dos próprios campos já constituídos, levando sempre o mais longe possível a especialização do conhecimento. Claro está que o eixo dessas particularizações e parcelamentos se fez, na maior parte dos casos, buscando estabelecer e fortalecer o vínculo com a ciência e, por este motivo, pode ser lido como estratégias de aquisição de status e poder particulares (FOUCAULT, 1979; 2003).

\footnotetext{
Conforme FOUCAULT, M. Microfísica do poder. Rio de Janeiro: Graal, 1979._. Estratégia, poder-saber. Rio de Janeiro: Forense Universitária, (Coleção Ditos e escritos IV), 2003.
} 
Essa separação identificada e denunciada na aurora do design moderno é, sem sombra de dúvida, uma operação insistentemente realizada no capitalismo: a instauração da lógica das divisões. Alguns autores identificam esse gesto operativo como uma estratégia de exercício de poder, de controle, de subordinação e dominação (FOUCAULT, 1979; 1995;MACHADO, 1990) ou de constituição de campo (BOURDIEU, 2004). Para se concretizar os efeitos positivos e/ou negativos de disciplinamento e controle, as divisões se mostram eficazes e eficientes.

Desse modo, sugere-se neste breve artigo que o design, na maior parte do seu desenvolvimento, se constituiu como campo de produção de conhecimento que se posiciona criticamente à proposta das divisões. Nascido nesse contexto, o design ao longo da sua história tem se debatido com esta problemática. Fala-se atualmente no esgotamento do projeto funcionalista. Certamente o fato do design guardar relação de maior ou menor intimidade com a arte, de se relacionar com o mercado sucumbindo ou não a ele e de manter a postura transgressora, adesista ou ingênua no fazer profissional, são índices que auxiliam a compreender a extensão do reproche dirigido ao funcionalismo (Villas-Boas, 1998).

\section{CONCLUSÃO}

O exame do conceito de ars, neste artigo, visou problematizar algumas questões concernentes ao design. Mesmo que o design enquanto campo de produção de saber, tenha emergido no contexto da modernidade marcado pela lógica das divisões, subsiste na sua matriz a dificuldade dessa lógica se firmar plenamente, haja vista o espaço fluido e transversal em que se desenvolve a atividade projetual. De alguma maneira, como já haviam apontado os "pais fundadores" do design, a relação do campo com a arte, com a arquitetura, com técnicas de caráter mais empírico e com tecnologias sofisticadas, sempre esteve (ou, ao menos deveria estar) na agenda dos designers. A noção de ars utilizada no medievo e resgatada pelos primeiros designers modernos aponta para isto. Os modos como os designers na contemporaneidade têm pensado e utilizado o espaço, por exemplo, na crítica aos grids e ao funcionalismo, nas sobreposições, fusões, recortes e transfigurações que fazem ao pesquisar materiais e desenvolver projetos de produtos, apontam para um espaço de liberdade criativa que em muito supera a ideia de representação tão difundida na atividade projetual. Para além das representações que se creem fazendo das coisas, estarão os designers, neste século XXI apresentando suas criações como faziam aqueles que utilizaram a noção de ars?

\section{REFERÊNCIAS}

ARANTES, Priscila e ANTONIO, Jorge Luis. As fronteiras entre o design e a arte. In: VALESE, Adriana (et al.). Faces do design. São Paulo: Rosari, 2003, pp.129-143. 
ARISTÓTELES. Ética a Nicômaco. Brasília: UnB, 2001.

BARBOSA, Carlos Alberto. Tékne e design: uma relação entre o conceito aristotélico de arte e o conceito contemporâneo de design. In: VALESE, Adriana (et al.). Faces do design. São Paulo: Rosari, 2003, pp.49-72.

BOURDIEU, Pierre. Campo intelectual e projeto criador. In: GODELIER et alii (orgs.) Problemas do estruturalismo. Rio de Janeiro: Zahar, 1968, pp. 105-145.

A gênese dos conceitos de habitus e de campo. In: O poder simbólico. Rio de Janeiro: Bertrand, 2004, pp. 59-74.

BRANDÃO, Antônio Jackson de Souza. Téchne: entre a arte e a técnica. Revista Litteris Filosofia, Julho 2010, Número 5. Disponível em: <http://www.revistaliteris.com.br>. Acesso em: 12 jun. 2011

BÜRDEK, Bernhard E. Design: História, teoria e prática do design de produtos. São Paulo: Blucher, 2010.

CAMPOS, Gisela Beluzzo de. A influência do objeto industrial na arte. In: VALESE, Adriana (et al.). Faces do design. São Paulo: Edições Rosari, 2003, pp.71-80;

Arte, design e linguagem visual. In: MOURA, Mônica. Faces do design 2 - ensaios sobre arte, cultura visual, design gráfico e novas mídias. São Paulo: Edições Rosari, 2009, pp.65-79.

CANGUILHEM, Georges. O normal e o patológico. 5. ed. Rio de Janeiro: Forense Universitária, 2002.

COST, Ricardo da. A Ciência no pensamento especulativo medieval. In: Sinais - Revista Eletrônica. Ciências Sociais, Vitória: CCHN, Edição no 5, vol. 1, set. 2009, pp.132-144.

DEBRAY, Régis. Vida e Morte da Imagem: Uma história do olhar no Ocidente. Petrópolis: Vozes, 1994, p. 230

DELEUZE, Gilles. Conversações. Rio de Janeiro: Ed.34, 1992.

. Mil platôs - capitalismo e esquizofrenia. Vol. 5. São Paulo: Editora 34, 1997.

DIAS, Maria Helena Pereira. Encruzilhadas de um labirinto eletrônico - uma experiência hipertextual. Campinas-SP: UNICAMP, s/d. Disponível em: <http://www.unicamp.br/ has/mh/principal >. Acesso em: 20 jun 2013.

DONDIS, Donis A. Sintaxe da linguagem visual. São Paulo: Martins Fontes, 1997.

ECO, Umberto (org.). História da Beleza. Rio de Janeiro: Record, 2010.

FOUCAULT, M. Microfísica do poder. Rio de Janeiro: Graal, 1979.

. As Palavras e as Coisas. São Paulo: Martins Fontes, 1995.

. Estratégia, poder-saber. Rio de Janeiro: Forense Universitária, (Coleção Ditos e escritos IV), 2003.

GARCIA, Alicia Olabuenaga De la tecnica a la techne. Disponível em: <http://serbal.pntic.mec.es/ cmunoz11/techne.html\#Inicio>. Acesso em: 15 jun. 2011

HABERMAS, Jürgen. Teoria de la acción comunicativa I - Racionalidad de La acción y racionalización social. Madri: Taurus, 1987. 
Teoria de la acción comunicativa II - Crítica de la razón funcionalista.

Madri: Taurus, 1987.

. Técnica e ciência como ideologia. Lisboa: Edições 70, 1987.

MACHADO, Roberto. Deleuze e a Filosofia. Rio de Janeiro: Edições Graal, 1990.

MEIRINHOS, José. O sistema das ciências num esquema do século XII no manuscrito 17 da Santa Cruz de Coimbra. Revista Medievalista online, ano 5, no 7, dez. 2009, Lisboa: IEM - instituto de Estudos Medievais. Disponível em http://www2.fcsh.unl.pt/iem/medievalista. Acesso em 02/06/2012.

MELO, Chico Homem de. Os desafios do designer \& outros textos sobre design gráfico. São Paulo: Edições Rosari, 2003, pp 62-69.

MORAES, Anamaria de. Design: arte, artesanato, ciência, tecnologia? O fetichismo da mercadoria versus o usuário/trabalhador. In: COUTO, Rita Maria de; OLIVEIRA, Alfredo Jefferson de (orgs.). Formas do design: por uma metodologia interdisciplinar. Rio de Janeiro: 2AB: PUC-Rio, 1999, pp.156-191.

ROUANET, Sérgio. As Razões do lluminismo. São Paulo: Companhia das Letras, 1998.

SANTAELLA, Lúcia. As aparições do belo. In: Estética: de Platão à Pierce. São Paulo: Experimento, 2000, pp.25-36.

SOMMA JUNIOR, Nelson. Artesanato: patrimônio cultural. In: MOURA, Mônica. Faces do design 2 - ensaios sobre arte, cultura visual, design gráfico e novas mídias. São Paulo: Edições Rosari, 2009, pp.145-151.

SPEER, Andreas. Tomás de Aquino e a questão de uma possível estética medieval. Viso - Cadernos de estética aplicada - Revista eletrônica de estética, № 4, janjun/2008. Disponível em http://www.revistaviso.com.br (acesso em 12 fevereiro 2014).

STRUNK, Gilberto. Viver de design. Rio de janeiro: 2AB, 2007.

VARGAS, Milton. Para uma filosofia da tecnologia. São Paulo: Alfa - Omega, 1994.

. História da matematização da natureza. Estudos Avançados, São Paulo, v. 10, n. 28, dez. 1996, pp. 249-276.

VILLAS-BOAS, André. Utopia e Disciplina. São Paulo, 2AB Editora, 1998.

23-29.

Interdisciplinaridade. In: Identidade e Cultura. Teresópolis (RJ): 2AB, 2009, pp.

WERTHEIM, Margaret. Uma história do espaço: de Dante à internet. Rio de Janeiro: Jorge Zahar, 2001. 